\title{
SOME MODERN FRENCH CONCEPTIONS OF HYSTERIA.
}

BY S. A. K. WILSON, M.B., B.SC., M.R.C.P.

Registrar to the National Hospital, Queen Square, London.

IN the early years of last century a small and unpretentious volume was published (long since out of print), by George Tate, Surgeon, entitled "A Treatise on Hysterical Affections," which opens in the following engaging manner: "It fell to my lot at the age of 22 to have almost the sole charge of an extensive country practice: and although I came down from the Hospitals, as I fondly believed, brimful of information, prepared to compass every case that might present itself, I soon discovered that neither books, nor Lectures, nor Hospitals, had made me quite the practical man I had vainly imagined.

"True, I did not fall into the error of mistaking muscular pain in the side for pleurisy, nor every disturbance of the heart's action for organic disease; but some extraordinary cases of an hysterical nature stupefied and confounded me, at the same time very seriously deranging my self-complacency. . . . I sought in consultations with older men a relief from my own bewildering doubts and cares; but in vain. They could throw little light upon the deep obscure. Hysteria may well be called-

'An Ignis Fatuus that bewitches, And leads men into pools and ditches.'

For the old gentlemen fell into as many quagmires as myself. Baffled and dissatisfied, I was compelled to think for myself, and determined, if possible, to discover some general distinctive marks that would stamp the character of hysterical disorders, and enable us to base the treatment on more rational and certain principles.

"The following pages disclose the results of my studies. . . . Hysteria, in all its varieties . . . . has one common cause which is essential to its appearance: namely, an irregular or defective menstruation. Since I have been attentive to cases of Hysteric disorder, I have never seen one (with certain unimportant exceptions) either of a simple or of a complex character, in which this state of things did not co-exist."

The quaint old-world flavour that pervades the pages of this little volume is very refreshing, but the quotation has been made with another 
object. Hysteria is coeval with the human mind, and ever since there have been physicians at all, what has characterized the labour of many if not just this same determination to discover the distinctive marks of hysterical disorders and thereby to lay the foundation of a rational therapeusis? That the search is being prosecuted with undiminished ardour to-day can only mean that hitherto it has not been crowned with success. George Tate discovered the key, as he thought, to the problem of hysteria in an irregular or defective menstruation, and his views may not unfairly be taken as representative of pre-Charcot opinion, although both Brodie in England and Briquet in France were aware of their insufficiency and looked elsewhere for a solution of the mystery. If we pass to the epoch associated with the name of the beloved "Maitre" of our French colleagues we find hysteria conclusively demonstrated to be no doubtful privilege of the female sex; its occurrence in men became an accepted fact: it was "la grande névrose," " une maladie psychique par excellence," "la grande simullatrice" of all sorts of organic disease. With the passing of the years the professional hystériques of the Salpêtrière, so assiduously cultivated by Charcot, have gone, or almost gone-although, as Dubois reminds us, some, like old circus horses, can still be found doing their turn-but no one who has known the wards of that famous Hospice as they used to be will deny the reality of the phenomena that once drew the whole medical world to Paris.

Charcot's views were expressed with authority, and enunciated with dogmatism, but they have not been stamped with the seal of finality. The last twenty years have witnessed renewed efforts to solve the enigma. Developing the psychical side of the disease on the lines laid down by Charcot, Janet, of the Collège de France, a psychologist of whom France may well be proud, has, in many volumes and communications, propounded and defended a frankly psychological theory of hysteria, according to which the affection "is a form of mental depression characterized by the retraction of the field of personal consciousness, and a tendency to the dissociation and emancipation of the systems of ideas and functions that constitute personality." On the other hand, Babinski, the brilliant clinician of La Pitié, amplifying in his turn a dictum of Charcot's that to be hypnotizable is to be hysterical, and that exaltation of suggestibility is common to hypnosis and hysteria, has elaborated a definition of the latter condition in the following words: "Hysteria is a special mental state capable of giving rise to certain symptoms that have features of their own. It manifests 
itself by primary and by secondary disturbances, the former being characterized by this, that it is possible to reproduce them by suggestion, with rigorous exactness, in certain subjects, and to make them disappear under the sole influence of persuasion."

Meanwhile, in Austria, Sigmund Freud, of Vienna, has during the last fifteen years promulgated still another psychical hypothesis of hysteria, and has modified and substantiated it in successive publications. Freud has probed the depths of his patients' minds always to discover ample corroboration of his contention-which, with all the changes he has otherwise made has never been abandoned-that " in a normal vita sexualis no neurosis is possible." "He who can interpret the language of hysteria can understand that the neurosis deals only with repressed sexuality." A thousand years have flown by, as Aschaffenberg reminds us, since the uterine hypothesis of hysteria led captive men's imagination, and in the sexual sphere once more is the search for light being prosecuted, but, no doubt, with a saner enthusiasm.

On the physiological side, however, endeavours have been made to devise a pathogenic theory at once comprehensive and satisfying. Sollier, of Paris, has defined hysteria as a disease associated with "a condition of cerebral torpor, or cerebral inhibition, a specialized sort of sleep analogous to what has been called vigilambulism." In England, McDougall has, in a recent article, sketched a suggestive and purely physiological theory of hysteria. There are other modern views on hysteria associated with the names of Raymond, Binswanger, Oppenheim, Mills, Hellpach, and Vogt. Finally, Dubois, of the University of Berne, states categorically that "it is useless to make an effort to give hysteria the character of a morbid entity," and this negative attitude is also that of Steyerthal.

The mere enumeration of these conflicting hypotheses may overwhelm the reader with a deep sense of despair at their hopeless dissimilarity, and he may reasonably fear that finality is as far off as ever. But let him not be unduly distressed. Odd as it may appear, many of these contradictory opinions have one feature in common. Not only are the respective originators alike in the earnestness of their advocacy of them, but there is a curious similarity in their appeal to their own clinical experience subsequent to the adoption or enunciation of their own particular theory, and in their resort for substantiation of its virtues to the results of treatment. Thus George Tate says: " Since I have been attentive to cases of Hysteric disorder I have never seen one . . . . in 
which this state of things "- -an irregular or defective menstruation-—" did not co-exist." Further, "since the first publication of this little work an experience of many years has afforded the opportunity of testing upon a large scale the somewhat original views I have maintained upon this subject . . . . I can add nothing that would materially affect the principles or alter the practice propounded many years since. In my own hands the results of that practice have been signally successful: and so many acknowledgments bearing similar testimony have reached me from various quarters that . . . . I hope to be acquitted of an overweening confidence." Or Freud: "In all cases that I have analysed it was the sexual life that has furnished a painful affect. . . . It is not theoretically excluded that this affect could not occasionally originate in other spheres, but I must say that thus far I have found no other origin." And again, "I do not claim that I have actually removed all the hysterical symptoms which I have undertaken to influence by the cathartic method, but I believe that the obstacles were due to the personal circumstances of the cases, and not to the general principles." Or Babinski : "My conception can thus lay claim to a nosological principle that has undergone the test of time, for it is in conformity with the ancient adage: Naturam morborum curationes ostendunt." And again, "In the great majority of cases I have been asked to treat I have obtained a rapid cure. Sometimes, however, . . . . I have been obliged to exhibit a great deal of perseverance in treatment. I also admit one or two failures, but perhaps these were cases of ordinary simulation." Or Sollier: "I may rely on the same adage as M. Babinski to demonstrate the truth of my physiological theory of hysteria, for it is based on the adoption of a pathogenic therapeusis . . . . I mistrust the validity of the principle, however. . . ." And again, "I have treated more than 200 cases, which have served only to confirm my belief in my theory, a theory which the results of treatment have shown, as by an actual laboratory experiment, to be true. All the physicians in France and abroad who have taken the trouble to verify my experiments and my methods have obtained identical results." Or, finally, not to weary the reader, Dubois, who declines to separate hysteria from neurasthenia: "If I dare to face the criticism of my colleagues, it is first because I feel that I am upheld by the friends who have become interested in my ideas; but, above all, it is because in the practice of my treatment by psychotherapy I have had such good and lasting results, that I should like to put into the hands of young physicians the instrument which I have found so useful." 
To the individual who is not so absorbed in science as to lose his sense of humour it may seem that Hysteria, the while she responds so nobly to the appeals of the advocates of these various theories, is quietly smiling in her sleeve. As of old the ascetic and the epicurean, the celibate and the polygamist, the socialist and the monarch by divine right turned alike to the pages of Holy Writ for support of their particular ways of living and views on life, and found it therein, so the exponents of the sexual theory, the suggestion theory, the sleep theory, and the "hysteria-only-a-symptom" theory, alike appeal to experience for confirmation of their opinion, and find it. It seems to me that not only does the mere juxtaposition of the above selected passages furnish a self-evident proof of the fallaciousness of this appeal to the results of treatment, as Sollier himself has clearly recognized; it also affords a significant illustration of what appears to be as unfortunate a tendency in the study of modern hysteria as in the study of the ancient, viz., the introduction, consciously or unconsciously, of the subjective element, as I suppose for want of a better term it must be designated, on the part of the physician. More than one speaker at the recent Discussions on hysteria held by the Neurological and Psychiatrical Societies of Paris made allusion to this fact, but it has not been emphasized at all adequately. It is not merely that his hypothesis is apt to colour the physician's way of looking at a case, but also that in some obscure and little understood manner the patients come in a sense to respond to his hypothesis, so that the wider his experience the greater is the apparent confirmation of its truth. How else can we explain the facts so familiar to the student of the history of the disease? The clinics of Paris and Vienna have shown us how hysteria can be cultivated; the hysterical patients of the Salpêtrière differ from their fellows of the Pitié. In a hundred consecutive cases Babinski has failed to discover a single instance of hemianæsthesia: "as for constriction of the visual fields, dyschromatopsia, ovarian tenderness, and so on, the hystériques in my wards simply do not have them." "Heureuses hystériques!" says Sollier in an aside.

There is, I think, a profound truth in the remark of the late Professor Raymond, that the patients do not change so much as is thought; it is rather that the observer changes his point of view. Any one who reads the contributions of Freud will be struck by the way in which, in his earlier communications, he describes his open-mindedness in approaching the problems of hysteria, and how the juvenile sexual trauma eventually forced itself on his consideration till he became convinced of 
its essentialness. Wherever he looks now, it meets his gaze. We may say, if we will, that there are differing hysterical " types," but the interesting thing is that these types appear wherever the disease is cultivated, and that in a matter of this kind the subjective element must enter largely. Nor can the influence of environment, circumstances, and that indefinable something which is usually called the "atmosphere" of a place be ignored. Let the reader turn to the fascinating essay on "The Wandering Jew" from the pen of Henry Meige, which appeared long ago in the Nouvelle Iconographie de la Salpêtrière, to appreciate what the reputation of Charcot and the atmosphere of the Salpêtrière meant to the world of hysteria.

Here in England hysteria has never been cultivated. For some reason, the English neurologist has been far more concerned with organic than with so-called functional nervous disease. Not that hysteria or any of the other psycho-neuroses is a rarity; on the contrary, a six years' experience at the National Hospital in Queen Square, has afforded me opportunities of seeing cases of functional disease in abundance. But while English neurology has made many noteworthy contributions to the study of organic nervous disease, it is scarcely any exaggeration to say that hysteria has been left to itself. Curiosity has led me to scan the indices of the last ten volumes of BRAIN with the following result: out of something like 350 original articles and reports of clinical cases there are at the most ten relating, and some of these only indirectly, to disease of the nervous system of a functional sort. If there has been no school or hospital with an avowed penchant for the hysterical, no "Maitre" to promulgate original views or disseminate the opinions of others, then the examination of our abundant clinical material has a value of its own and becomes of scientific importance, not only because of the absence of mental prepossession on the part of the examiner, but also because of its prosecution almost entirely-I speak of the methods in vogue at the National Hospital-on objective lines. It is on the adoption of the objective point of view that our expectation of progress towards the unification of the disease must depend. From such methods of procedure facts can be gleaned which may be shown to be full of significance for an explanation of the psycho-physiological mechanism of the diverse phenomena of hysteria.

In the following pages a résumé of the hypotheses associated with the names of Babinski and Janet will be given, and acknowledgment made of the great merits of these theories, and of the services they have already rendered towards the elucidation of the subject. Various 
points on which the hypotheses are open to criticism will be referred to, in support of which sundry clinical cases will be quoted. One or two matters already briefly noted in this introduction will be more fully discussed, and a scheme whereby to approach the problem of hysteria from the objective standpoint outlined. For permission kindly granted me to refer to various cases under the care of different members of the Medical Staff of the National Hospital, every one of which has been personally observed, I wish here to express my most grateful thanks.

\section{CHAPTER I.}

\section{Babinski's Conception of Hysteria.}

For a right understanding and appreciation of the attitude now adopted by Babinski towards the problem of hysteria, it is essential to preface an account of his views with one or two brief, but none the less important, considerations. Since the title of his most important contribution to the subject is "The Dismemberment of Traditional Hysteria," we must be perfectly clear as to what he really intends thereby.

We must first disabuse our minds of the idea that where hysteria is concerned, the "Salpêtrière school" and the "French school" are interchangeable terms. In spite of the dogmatism that characterized it, Charcot's teaching was never accepted in its entirety by some of the French provincial schools, notably the small but very active one at Nancy. At the latter place, Liébault and Bernheim found themselves in direct antagonism to Charcot on the important, and, as it once appeared, fundamental question of the relations between hysteria and hypnotism. Charcot taught that the two were intimately associated, that to be hypnotizable was to be hysterical, and to be hysterical was to be hypnotizable. Time has shown the inaccuracy of these opinions, for most experts are agreed that hysterical patients are difficult to hypnotize, while so large a percentage of normal individuals are hypnotizable, that the idea of their all having latent hysteria is absurd.

Again, the comparative paucity, at least in the Charcot days, of the contributions to the study of the neurosis emanating from observers in Germany, England and America, may not unfairly be taken, in one sense, to be an expression of an undercurrent of feeling that "traditional hysteria" was peculiar to Paris, and that it was necessary to go to Paris to observe it. Hints of this sort were openly expressed by some 
German clinicians. It is not so to-day, of course, for once the didactic descriptions of Charcot permeated the text-books of these countries the disease was more readily diagnosed and, as is always the case, instances of it seemed to multiply. In spite of the fact, however, that full-blown hysteria can be found in Berlin or London, or, for that matter, in any country village, in as complete a form as in Paris, there has been a vague or tacit disinclination on the part of other medical schools to subscribe wholeheartedly to the dicta of the great French observer. Just as clinical experience has long ago furnished proof of the relative rarity, in this country at least, of the "classical" type of disseminated sclerosis, according to Charcot's masterly exposition, as compared with "formes frustes," so there has been a feeling that the "classical" hysterical patient is a rara avis, and that many of the bizarre symptoms complacently attributed at the Salpêtrière to the great neurosis were thus classified through ignorance of their real significance. When, therefore, Babinski attacks the citadel of "traditional hysteria," we must remember that some never considered it to be in a strongly entrenched position, while it has long shown signs both of the assaults of critics and of the ravages of time.

On the other hand, it must not be forgotten that Charcot himself was fully convinced of the psychical nature of the affection, and when he determined the important rôle played by the "idée fixe" in the genesis of its symptoms it must not be overlooked that he was formulating a psychological hypothesis which his successors have merely amplified and elaborated. It was his to have demonstrated, by scientific methods, the possibility of reproducing hysterical symptoms experimentally by suggestion and of effecting their disappearance in similar fashion. Now let it be said at once that in Babinski's opinion hysteria is a disease of the psychical level, and that the relation of suggestion to its phenomena is cardinal. In what sense, then, have his criticisms resulted in a dismemberment of traditional hysteria?

In a famous lecture on hypnotism and hysteria delivered at the Salpêtrière on June 23, 1891, Babinski said: "mon intention . . . . est de vous rappeler cette vérité, dont il est indispensable d'être bien pénétré, que le domaine de l'hystérie est infiniment plus vaste qu'on ne croyait autrefois." In his brochure of 1909, he says: "tous les médecins reconnaissent actuellement que le domaine de l'hystérie traditionelle a été démésurément étendu." To read these two statements consecutively is to appreciate at once the change in Babinski's point of view, and the latter of them may be taken to constitute his first criticism. 
(1) The term "Hysteria" has become too Comprehensive.

In the world of medical thought there always have been sundry conceptions, unstandardized and variable, sometimes defaced and depreciated, which nevertheless pass as current coin. By their aid we often win credit where none is due, for classification and diagnosis are not synonymous. Half a dozen such readily suggest themselves. "Neurasthenia," "neuritis," "hysteria," are veritable godsends to the incompetent or the indolent. Of any of them might be said what Lasègue said of the last: "It is a basket for papers we don't know where to place." Gowers has varied the metaphor by declaring that "hysteria is a conception that conceals whatever it covers; we must rescue from it whatever we wish to study." Everyday observation teaches us that vagueness in our connotation of a nosological term has for sequel the unjustifiable multiplication of apparent instances of the disease. And conversely, if we seem to find cases of a given disease wherever we turn we may well question whether our conception of it is sufficiently precise. These remarks may be applied pertinently to the subject of discussion. To the student more particularly of the French literature of hysteria there will recur, as he turns over the pages of his "Charcot," not only the wonderful attacks in all their stages, the stigmata, the somnabulisms, the "fugues," the multitudinous motor and sensory phenomena, the paralyses, contractures and tremors, the anæsthesias and hyperæsthesias, but also the hæmorrhages, hæmatemeses, hæmoptyses, erythemas, the ulcerations and even gangrenes, the inflammations, œdemas, anurias, polyurias, hæmaturias, and albuminurias-in short, the whole gamut of symptomatology, until he puts away the volumes to seek relief in the comforting generalization, that "l'hystérie peut tout faire."

We must beware, however, of assigning all responsibility for the production of this conglomerate to Charcot himself; his successors extended the hysterical horizon immoderately, till the conception of hysteria was bounded only by the limits of the mind itself. It is sufficient in this connection to remember that Möbius, one of Charcot's followers, considered all morbid phenomena hysterical that were produced by ideas, but the broader such a conception is, the shallower it becomes.

No one, then, will quarrel with Babinski when he proceeds to examine the causes of this unwarrantable extension of hysteria, and finds it has been determined by erroneous diagnosis, by undetected fraud or simulation, and by the inclusion of symptoms common to 
other morbid conditions, or by the confounding of certain nervious states that ought to be distinguished. Of course, these are exactly the causes of the unjustifiable extension of the limits of any nosological entity; there is nothing specific about them. They apply equally well to neurasthenia. That the domain of hysteria, however, has come to range from insanity to renal disease, and from doubled personality to gangrene, is ample evidence of the necessity for a complete reinvestigation and restatement of the problem, and therefore Babinski's first contention, which he has persistently brought before the profession during the last ten years, is one that commands universal approbation.

(2) The Codification of Hysteria has been too Artificial.

In his cliniques Charcot encountered the difficulty with which all teachers are confronted, namely, how to combine the proven and the not proven in the presentation of a subject suitably to the requirements of the student. An authoritative personality such as his could not be content to doubt; consciously or unconsciously his views were propounded with an increasing degree of dogmatism, until the conception of hysteria, stretched to the utmost, lost its elasticity, and became fixed. In this fully organized form it may be sketched as follows.

Hysteria manifests itself by two classes of symptoms, one comprising what are known as fixed stigmata, the other transitory. Of the stigmata, which in addition to being permanent usually develop independently of the patient's knowledge, we may specify hemianæsthesia, anæsthesia of the throat, unilateral affection of the special senses, constriction of the visual field and dyschromatopsia, also "points douloureux," ovarian tenderness, \&c. Among the transitory or mobile phenomena are fits, attacks, crises, palsies, contractures, tremors, spasms, aphonia, mutism, \&c., which usually appear suddenly, under the influence of an emotion, and may disappear equally suddenly. In addition to these two classes, a long train of complications, cutaneous, vasomotor, trophic, \&c., ought to be mentioned as included in the conception.

Now while cases illustrating many or most of the above-mentioned features, and constituting an hysterical museum, assuredly do not run about the streets, yet under the influence of Charcot's teaching, once a diagnosis of hysteria was made, the examiner almost invariably endeavoured to detect one or other of the stigmata, hoping thus to bring his case into line with the classical description of the disease. The discovery even of a single symptom apparently of an hysterical nature was enough for 
this purpose. There can be no doubt that by procedures of this sort patients were directly, if unintentionally, invited to bring symptoms and signs into being. Such was the result of the codification of hysteria.

Against this manner of thinking and way of examining Babinski has declared himself fundamentally opposed. Investigations conducted without any preconceived ideas have led him to the conclusion that the so-called stigmata are not characterized by any fixity, "except in the case of certain professional hysterical patients, for whom the disease is a means of livelihood, and who are simulators rather than patients." Further, he denies that the patient's ignorance of the presence of these stigmata constitutes a cardinal feature; they are the consequence either of auto-suggestion, or of unconscious suggestion on the part of the examining physician. If only sufficient care be exercised, hemianæsthesia, visual constriction, ovarian tenderness, \&c., are conspicuous by their absence. "Les hystériques de mon service n'en ont pas." In one hundred consecutive cases of hysteria in both sexes, patients who had not undergone any previous neurological examination, he failed to find a single instance of hemianæsthesia. Tactile, painful, temperature, muscular, and stereognostic impressions were all tested. A statement like this, from a clinician of world-wide reputation, is a very remarkable one, and merits weighty consideration.

Similarly, the features supposed to be characteristic of the transient symptoms of hysteria-their relation to emotion, and suddenness of appearance and disappearance-are not peculiar to hysteria and cannot therefore serve as distinguishing marks. They cannot be utilized for purposes of definition.

We may here remark that Babinski is avowedly in search of criteria by which to define the disease, a notoriously delicate matter, especially since it is hysteria that is concerned. The determination and statement of its proper characters are no doubt all that is required, and in strict conformity with principle, but even though there should be unanimity on the subject of what pertains to hysteria and what does not, a definition depends so much on the point of view of its creator that it may not meet with general acceptance. One of the most curious things about hysteria is just this, that while there is seldom any difficulty in coming to a diagnosis between it and organic nervous disease, and while there is a wide symptomatology accepted by the whole medical world as hysterical, agreement on a definition of the affection is still very far from being achieved. The explanation lies partly in the fact that misunderstanding may arise on the nature of a definition. 
The latter may be nosographic or it may be pathogenic; in other words, it may consist of an attempt either to summarize the pathognomonic symptoms of a disease, or else to bring into relief the connection between the nature of the disease and the symptoms to which it gives rise. We shall discuss later the definition of hysteria framed by Babinski, but we must remember that in his criticism of traditional hysteria his methods throughout have been constructive as well as destructive, and that his goal has been the establishment of a definition.

We have seen, then, the profound dissatisfaction with which Babinski regards the standard symptomatological descriptions of hysteria; but it must be noted clearly that he does not gainsay the reality of the symptoms themselves. He accepts the great majority of them, denying only the importance of the attributes of fixity, abruptness of appearance and disappearance, transience, independence of the patient's knowledge, \&c., attached to them, and independent investigation leads him to the conclusion that they may be characterized in another way. The points on which stress has hitherto been laid in the delineation of hysterical symptoms and signs are not, in his opinion, the proper points to emphasize. His contention is, that the manifestations of hysteria have only two attributes that are cardinal, essential, and sufficient-viz., on the one hand, the property of being reproducible by suggestion, with rigorous exactitude, in certain subjects, and on the other hand, of disappearing under the exclusive influence of persuasion.

Since these attributes of the symptoms of hysteria have met with considerable adverse criticism, we must specify the sense in which the terms are employed. By "suggestion" Babinski intends to express the process by which we endeavour to make someone accept or realize an idea which is patently irrational. To tell him on a fine, dry day that it is cloudy and pouring with rain, is to "suggest," for the allegation is in flagrant disaccord with observation; to tell a patient whose muscles function normally that he is hemiplegic or paraplegic is similarly to " suggest." On the other hand, to assure a patient that the "paralysis" from which he is suffering will vanish at once, by the aid of the will, or by electrotherapy, or any other means, is to "persuade."

Babinski has amplified his selection of these attributes into a definition which, in its latest version, is couched in the following terms :-

Hysteria is a special psychical state capable of giving rise to certain disturbances with characters of their own. 
It manifests itself principally by primary symptoms, and by secondary or accessory symptoms.

The former can be reproduced by suggestion with rigorous exactness in certain subjects, and can be made to disappear under the sole influence of persuasion.

The secondary symptoms are strictly subordinated to the primary ones.

Armed with this definition, derived from an independent study of the symptoms of hysteria, Babinski proceeds to reconsider these symptoms in the light of the knowledge thus gained, using his definition as a touchstone.

(1) Some of the symptoms characterizing "classical" hysteria can be reproduced by suggestion, others cannot. To those which can thus be reproduced, and removed by persuasion, he proposes to apply

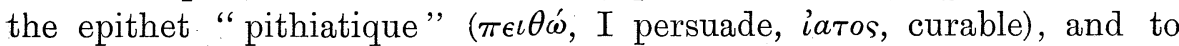
denominate the process " pithiatisme." As far as I am aware, Babinski nowhere supplies a detailed list of the symptoms which he has been able to reproduce successfully "in certain subjects," but a quotation will serve to indicate the more important of them :-

"The principal are convulsive attacks, paralyses, contractures, highly variable in their localization and intensity, tremors, choreic movements, sometimes irregular but usually rhythmical, troubles of phonation and respiration, disturbances of sensibility (anæsthesia or hyperæsthesia), disturbances of the special senses, bladder troubles . . . Suggestion is incapable of exaggerating or abolishing tendon reflexes, of altering the pupillary or cutaneous reflexes . . . It cannot produce vasomotor, secretory, or trophic affections, nor can it create hæmorrhages, anuria, albuminuria, or fever."

(2) There are other symptoms often associated with hysteria, and usually held to constitute as integral a part of the conception as any of the pithiatic symptoms. These are more particularly liable to arise as a sequel to an emotional shock, and are referred to by Babinski as "emotive." While he considers that, speaking generally, the rôle of emotion in the genesis of hysterical symptoms has been grossly exaggerated, he does not deny that it is incontestably the direct cause of the appearance of some symptoms, viz., tachycardia, vasomotor changes, erythema, disturbances of cutaneous and intestinal secretions. The essential difference between these symptoms and those of the first group is that the former are independent of volition, while the latter, in form, duration, and intensity, are determined by it. 
(3) There are still other signs, usually included in the conception of hysteria, which concern reflectivity, viz., generalized exaggeration of the tendon reflexes, and impairment of the cutaneous vasomotor reflexes (dermatographia). This group is fundamentally different from the first two, inasmuch as the phenomena are independent of any psychical influence, and have nothing to do either with suggestion or emotion.

'Tested, then, by the suggestion criterion, the symptoms of hysteria are seen to fall into three groups, immiscible and unassimilable. In the opinion of our author, comparative researches negative the possibility of the establishment of any intimate relation between the first group and the other two. As a consequence, it is irrational to apply the same terminological expression to all; then why, he asks, prolong the usage of the word hysteria? Convention will decide the matter, but misunderstanding can be most easily avoided by the adoption of the term " pithiatism," to indicate the autonomous group of symptoms comprised in the first of the above categories.

If the reader has followed this brief sketch of the rise and development of Babinski's present views on the subject, he will recognize that they are practically a generalization from an opinion of Charcot, as has been pointed out by various writers, and as has been already mentioned in the introduction to this paper. His statement, in the opening paragraph of his brochure, that the results of his researches have induced him to abandon the doctrines of his illustrious chief, must be understood in the light of his criticisms already referred to, that the domain of hysteria has been unwarrantably enlarged, and its codification has been too rigorous. So far from abandoning the doctrines of Charcot he has taken one of the latter's main contentions, and made its absolutism a test for all clinical data that seek admission to the syndrome. Now while Charcot was probably one of the first to demonstrate scientifically and experimentally the action of suggestion, we must remember that long before his day it was fully recognized, if little understood. If we turn to the pages of Mesmer, we shall find ourselves in a world of magnets and metallo-therapy, but it is one in which the part played by suggestion in the development of palsies and anæsthesias is richly exemplified though imperfectly appreciated. Or if we scan the instructive appendix to Paul Richer's "Hystéroepilepsie," we shall come across innumerable instances of the same process, and of the closely allied process of imitation, at work through the ages. Not only so, we shall find hysterical symptoms disap- 
pearing, as they do to-day, under the magic influence of persuasion. What though the "persuasion" may not always have been of the gentler sort? After all, it was but an exteriorization of the thought of the time, and we could not expect the spiritual healer of the Middle Ages to have ignored the power of the temporal arm of the Church. "Les grandes victimes de l'hystérie," on the other hand, form a small army to bear witness to the occasional failure of "persuasion." At the discussion Ballet particularly emphasized the fact of the antiquity of the symptoms known as "troubles par suggestion." What Babinski has done, then, may be put in another way. He has taken indisputable hysterical symptoms and analysed them afresh from the point of view of the common features they present; and among these the only character he can find that is not only common to all, but peculiar to all, in the sense of distinguishing them from all other disease symptoms, is this possibility of reproducing them by suggestion, with rigorous exactness, "in certain subjects," and of making them vanish under the sole influence of persuasion.

It is no little service to have cleared the air in this fashion. With that desire for precision which is one of the distinguishing features of the Gallic mind, Babinski has set before himself the laudable aim of reorganizing an unwieldy nosological conception and of limiting the sphere of its operation. By selecting what appears to be a characteristic of most hysterical phenomena for a diagnostic and pathognomonic sign, he has occupied a strong position, which we may now proceed to examine in greater detail.

In the first place, we owe him a debt of gratitude for exposing the ease with which faulty methods of examination can originate hysterical symptoms. Mankind falls an easy prey to suggestion. There is a tale of some traveller, a wretched sailor, who, late one evening, went on board a liner on the Manchester Ship Canal, under the impression it was to sail at once. He was violently sick all night, but in the morning found to his disgust that the boat had not stirred from the quayside. In hysteria the suggested idea is paramount. The hysterical subject is incredibly sensitive to suggestion. Merely to mention a symptom is to bring it into existence, sometimes with a rapidity that is bewildering. I well remember a case of severe hysterical paraplegia in a young woman who had been seen by several physicians in consultation, one of whom came to the conclusion that the case was one of chronic myelitis, but admitted, unfortunately in the patient's hearing, that it was odd there were no bladder symptoms. The patient promptly 
obliged by developing incontinence of urine, which continued for six weeks! Of course, the hypersuggestibility of the hysterical patient is notorious, but the point for the examining physician to keep steadily before him is his responsibility in view of this trait in the hysterical character. To my mind, the greatest service Babinski has rendered to the study of the subject is his demonstration of the frequency with which the so-called stigmata of hysteria have turned out to be the fruit of unconscious suggestion. Reference has already been made to his series of a hundred cases of hysteria in which no trace of anæsthesia was discoverable, and to his failure to detect any constriction of the visual field, dyschromatopsia, ovarian tenderness, \&c., under similar conditions. At the discussion there was remarkable unanimity as to the frequency-though not the constancy-with which hysterical anæsthesias are attributable to maladroit investigation. In such cases, as was remarked in the introduction, we have convincing evidence of the curious way in which clinical experience reacts upon nosological conceptions, which, in their turn, colour our interpretation of clinical phenomena.

In the next place, the firm stand which Babinski has taken in casting grave suspicion on the advisability of allowing such symptoms as hæmatemesis, hæmoptysis, hæmaturia, albuminuria, anuria, or such skin conditions as pemphigus, or such trophic lesions as ulcers and gangrene, to enter the category of hysteria, has had a salutary effect. As Jelliffe says, hysteria is no longer a morbid entity, it is a cohors morborum, and it is high time the work of critical disintegration had full play. Cases with the above-mentioned symptoms have been published that are certainly difficult of explanation except on an hysterical basis, but to dogmatize thereon is a serious mistake. Many observers, no doubt, never having had any experience of such symptoms in their cases of hysteria, have legitimately questioned the appropriateness of assigning them to the great neurosis, in the apparent absence of organic disease, and this, of course, is the attitude to be adopted, and that ought always to have been adopted. It is the case, nevertheless, that such symptoms have been ascribed to hysteria in its faculty of tout faire, hence the desirability of removing them outside the pale altogether-any of them may be put back again if necessary. If mistakes have occurred in assigning to hysteria nervous symptoms, which have afterwards turned out to be of organic origin, how much more likely are they to happen when the symptoms in question cannot be said to be nervous at all, in the ordinary sense? 
Babinski, too, has given the weight of his clinical authority to all proposals or methods which have for their object the removal of the hysterical patient from circumstances or environment likely to influence him or her in a deleterious way. The direct outcome of his views on hysteria is a vivid appreciation of the harmfulness of imitation and contagion where highly suggestible patients are concerned. It is a commonplace that the whole modern treatment of hysteria, whatever be the theory of the physician, represents a radical change of front from the position of thirty years ago, but this change has seemed to be so natural a development that it is impossible to apportion the credit to any particular individual or school. Babinski's views on the neurosis, however, make it logically imperative for anyone who holds them to treat his hysterical patients in a fashion that is calculated to result in nothing but good. The days are gone when the physician entertained the possibility of studying symptoms and of curing them at the same time.

The views which Babinski has promulgated have met with a good deal of adverse criticism, as anyone can see for himself who reads the discussions at the Société de Neurologie of Paris, and at the joint meetings held with the Société de Psychiatrie. The official report of the joint meetings alone occupies 136 pages of the Revue Neurologique. Among those who have not been converted are such well-known names as Dejerine, Raymond, Ballet, Janet, Pitres, Sollier, Cestan, Dufour, \&c. Others who have criticized adversely are Oppenheim, Claparède, Jelliffe, Vogt, \&c.

Criticism may be directed (1) towards the definition of hysteria proposed by Babinski, and (2) towards the views on which that definition is based.

(1) As has already been pointed out, a definition may be regarded as either nosographic or pathogenic; either it is intended to express concisely the pathognomonic symptoms of a disease, in which case it must be the final outcome of a synthetic study, and not a fundamental condition of this study, or it may represent an attempt to express the hypothetical nature of a disease and the pathogenic relation in which the symptoms stand to it. Now we have seen that Babinski has evolved his definition from a consideration of certain unmistakeable hysterical symptoms, and with this definition as a criterion he proceeds to test the very symptoms from a study of which he has derived it. We are, therefore, left in doubt whether it expresses a theoretical opinion as to the 
nature of hysterical disorders, or whether, in Claparède's, words, it is simply an empirical enunciation of a diagnostic sign. At the opening of the discussion Babinski contended stoutly that delimitation of a subject must precede its systematic study, but several members who took part protested against this method of procedure, on the ground that his demand was legitimate only if the delimitation be accepted as a provisional approximation. Yet this is not the attitude Babinski has assumed. He makes his definition a Procrustean bed on which he lays the phenomena of the disease, which are as a result either lopped off without compunction, or stretched and strained so that they are made to fit it. In my opinion the writers who have condemned its artificiality have every justification for so doing (Claparède, Sollier, Crocq, Oppenheim, Raymond). While it may be admirably applied to the pithiatic symptoms of hysteria it leaves out other symptoms frequently found in association, though not perhaps reproducible "in certain subjects" as the former are. Forcibly to eject them, on this ground only, from the category of hysteria, is, as Raymond says, "to sin against nosology."

Sollier, further, has criticized the definition itself in a trenchant manner, and indicated the petitio principii which is involved. If hysterical symptoms are characterized by the facility with which they can be reproduced chez certains sujets-so indefinite is the definition-we may well wonder who these subjects are. Babinski says the procedure is " to observe suggestible individuals attentively and to experiment on them. Preference should be given to subjects formerly known as grands hypnotiques, for they possess an extraordinary degree of suggestibility. Others may be taken if they will lend themselves to investigation." We cannot avoid the uncomfortable feeling that some at least of these subjects are suggestible because they are hysterical. Thus the definition is not free from the grave ambiguity of leaving us uncertain whether it does not contain implicitly the very term which it seeks to define.

At the discussion another criticism of an entirely different nature was passed by Dufour, but it does not seem to have attracted the attention it deserves. It appears to me a very weighty objection indeed. Dufour remarked that " in accepting the definition we define a disease by the relations between the patient and the physician, thereby employing therapeutic rather than etiological terms. It is preferable to base it not on the influence which the physician exercises on the evolution of the symptoms, but on a consideration of the symptoms themselves freed of all pithiatic influence." I am fully convinced it is only by painstaking study of the objective characters of hysterical 
symptoms that real advance will be made, and it is one of the odd features of the hysterical controversy that Babinski who, more than any other clinician, has supplied us with precious objective signs to distinguish organic from "functional" disease, should base his definition and erect his symptomatology on an essentially subjective standard.

(2) (a) As a sequel to what has just been said of the definition itself, when we pass to consider the data on which the definition is based, the first point I wish to draw attention to is that we have no standard or criterion of suggestion or persuasion. They are measured by the personal equation, which is not a known quantity. Who is to decide whether a given symptom is hysterical in Babinski's sense or not? The criterion is subjective, not objective. Everything depends on the influence exercised by the operator, and success is not the prerogative of all. As far as persuasion is concerned Milne Bramwell, after years of special experience, expresses the following matured opinion: " Apparently the main factor for success is systematically repeated suggestion, but just what gives it its value I know not. Of analogous cases treated in this way by the same operator, some will recover and some will be uninfluenced. Again, while using identical methods, one person may succeed in a given case and another fail in an exactly similar one. Further, operators whose methods are widely different may be equally successful. Possibly the most important thing is not so much the method as the man behind the method." (The italics are my own.) Let us suppose a patient to be suffering from a flaccid palsy of the right arm, with no sensory disturbance, and that the practitioner is unable to decide from the imperfect history given him whether he is dealing with an hysterical monoplegia or a case of poliomyelitis. He finds no obvious indications of hysteria in the patient. Objective signs will enable him to draw a distinction immediately and with a minimum of doubt, but Babinski's definition demands the exact reproduction of the symptom by suggestion " in a certain subject." Well, our practitioner may be unable to effect this. Can it be removed under the sole influence of persuasion? Perhaps it may, but our practitioner, in spite of every endeavour, again may be unsuccessful. Thus its hysterical nature cannot be determined. Babinski responds that even when we fail we know that the palsy is susceptible of being cured by persuasion. But if we fail, how do we know? How can we possibly know?

In this connection two cases have been reported by Raymond, and are specially instructive because the nature of the symptoms was such as to lead the observer to suspect he was dealing with organic disease. 
One was a case where a cook suffered from odema of the hand, with complete hemianæsthesia of the same side of the body. Surgical and medical treatment alike were entirely ineffectual, while Charcot, to whom the case was referred, made a diagnosis of hysteria. After leaving hospital the patient came unexpectedly into a small fortune, when the œdema and the hemianæsthesia suddenly disappeared! It is true that Raymond had not thought of making that special suggestion which was the means of effecting a cure. Another patient, affected in a similar way, proved rebellious to all persuasive dialectic, but his voluntary immersion in the piscina at Lourdes was followed by instantaneous disappearance of his symptoms.

The point is that, if we argue from Babinski's diagnostic standard, these symptoms could not have been hysterical, yet the sequel showed that they were. They would have been thought organic had they not vanished as by the stroke of an enchanter's wand. Babinski's answer to somewhat similar objections to his conception of hysteria is, that in all probability the patients were told they would get better suddenly, even though the physician was himself unable to effect the cure, and that this was an auto-suggestion or a subconscious persuasion on which the patient acted when the psychological moment arrived. This is simply an assumption which it is impossible either to prove or to disprove without further information, and in any case, to leave the final determination as to the hysterical nature, or otherwise, of a given symptom to the off-chance of the arrival of the psychological moment is unsatisfactory and unpractical.

Or I might illustrate further by a reference to a case of hysteria, which I have had many opportunities of observing during the last two or three years.

A young woman came into hospital suffering from an hysterical spasm of the neck musculature. When this was modified under suitable treatment hysterical aphonia developed, and remained peculiarly rebellious to therapeutic measures. Faradization resulted in the aphonia becoming a complete mutism. Then, by way of change, the patient developed a remarkable spasm of phonation, so that she spoke extraordinarily loudly, but slowly and jerkily. This phenomenon changed again to mutism, and in spite of hypnotic measures and psychotherapeutic efforts of every description, persuasion remained an utter failure. Long after she had left the hospital and was living quietly at home, mute as ever, she found one evening in a box a pencil portrait of her dead father, in regard to which she had had a discussion with her aunt as to whether the head was drawn in profile to the right or to the left. She had maintained it was drawn to one side-it is immaterial which-while the aunt had thought it 
was to the other side. On discovering the sketch she suddenly cried out, "I'm right!" and then said, "Oh, I've spoken, auntie!" From that moment her recovery was complete and lasting.

Cases of this type are common and familiar enough. It is cited simply because it cannot be judged either by suggestive or persuasive criteria. Persistent interrogation failed to elicit any evidence of suggestion-there certainly was no suggestion that aphonia should be succeeded by mutism!-while persuasion was an abject therapeutic failure. Yet the case was patently one of hysteria, determined and diagnosed according to its objective characters. Where Babinski fails to cure a case by persuasion, he has reason to suppose that the patient is simulating. The young woman in question, however, was a school teacher, anxious to get back to work, and, moreover, particularly happy now that she is at last able to resume it. The assertion that such a case is at least susceptible of cure by persuasion, even though the observer fails, is entirely beside the point. How, I repeat, are we to know this? I do not deny for a moment that anyone examining this patient might say that her symptoms could be reproduced with rigorcus exactness "in certain subjects," and that, therefore, they come within the category of hysteria. Certainly, but how are we to decide that the reproduction is exact? The only possible way, surely, is by a comparison of the objective characters of the phenomena in the patient and in the subject experimented on. This at once takes us away from the criteria Babinski has endeavoured to establish ; there being no standard of suggestion or persuasion, we cannot appeal to them for diagnostic purposes.

But further, Babinski himself tells us that he has, by suggestion, been able to reproduce the symptoms of Sydenham's chorea with such exactness that he could not distinguish the copy from the original. Now if we cannot distinguish between the objective characters of a suggested chorea and an organic (not hysterical) chorea, there can be nothing specific in the symptomatic aspect of suggestion phenomena, and therefore they cannot be said to teach us anything.

(b) Babinski's tenets cannot explain adequately the frequent association of certain symptoms with pithiatic symptoms, nor the frequent occurrence in hysteria of phenomena originating apparently in simulation.

According to Babinski the realm of hysteria has been enlarged unwarrantably by the inclusion to an extraordinary extent of fraudulent cases. Everyone admits that conscious fraud would flourish were it not for the watchfulness of the physician; but, putting aside flagrant and gross malingering, we meet with apparently conscious simulation 
of a more subtle kind. Thus I have seen a patient with a complete hysterical hemianæsthesia stand beside her bed looking out of the ward window, and at the same time fumbling in the drawer of her locker with her anæsthetic hand to find a hairbrush, which she did quite easily. I have noticed a patient with profound paraplegia of the typical hysterical sort move her immobile legs while she lay half asleep. I have observed another patient, whose hysterical right arm hung helpless by her side, move it briskly to her face to avoid coughing in front of the physician. In each instance the patient offered no explanation of the incident, but simply repeated her tale of inability to move the limb, or of complete loss of feeling. These facts are of great interest, and their explanation is difficult. According to Babinski, there is no objective difference "between a suggested paraplegia and a simulated paraplegia; the only means of differentiating them is by a consideration of the state of mind corresponding. The simulator is conscious of his actions, while the suggestible individual is unconscious of them, or rather subconscious; " he is a sort of half-simulator." Whether this not very clear distinction can be maintained, even assuming that it can be detected, is highly problematical; in spite of the apparently volitional nature of the incidents above referred to by way of illustration, I do not think that the patient is fully conscious of his actions, and I certainly should not like to stigmatize him as an open fraud. It appears to me that the movements are volitional only in appearance, and that the conscious ego does not participate therein, so that no real distinction can be drawn between the two groups. It is therefore a serious defect in Babinski's views if he is unable by an appeal to their guidance to differentiate between what is suggested and what simulated. And it is surely a very weak position to adopt to say, that " the failure of psychotherapy, practised under good conditions and with perseverance, ought to incline to the belief that the case is one of simulation"; in other words, if we cannot cure a patient, then we must question his sincerity.

There are other phenomena of a simulated kind, which Babinski is unable to evolve by suggestion-viz., anuria and fever. And there are still others characteristic of so-called hysteria mutilans, in which erythemas, ecchymoses, ulcers, and various sorts of eruptions appear spontaneously, according to the protestations of the patient, but in reality as a result of some jugglery or artifice. Is it a mere coincidence that so many of these cases have shown symptoms of hysteria? Are they suffering from a psychopathic condition distinct and separable from that neurosis, or is there some link between the hysterical mind and this 
mythomaniac tendency? Our author, of course, would exclude them absolutely, not only because they cannot. be suggested, but because, not having any proper label attached to them, they have probably been thrown into the hysteria basket. Since their occurrence in combination with frankly hysterical symptoms is so frequent, for nosological reasons we ought to hesitate before summarily rejecting them. Take the following case :-

A young girl, aged 15 , with a marked neuropathic family history, had a sister who hurt her foot so that it turned inwards. The patient unconsciously copied this, and when her attention was drawn to what she was doing, the contracture became worse ; the toes were contracted and immovable, but found to be quite pliable during sleep. At the same time, wishing " to be coddled," "to be laid up for a little while," like her sister, she drove a large carpet tack into her right foot, but cannot remember whether it was painful or not. The foot became septic, and all sorts of complications ensued, but complete recovery eventually followed.

When aged 19, in order to make the mistress of her school, of whom she was passionately fond, love her more, she cut the back of her left hand with glass. It was not particularly painful. "I cut my glove, too, and pretended that I had been run into by a man carrying a frame of glass."

The next year, her mother being ill and in bed, the patient wanted to lie down, too, and " be made a fuss of." She therefore conceived the idea "it would be nice to have spinal disease." After waiting some weeks she procured some nitric acid, dipped a spun glass brush into it, and rubbed it up and down her back one evening. The back at once blistered and was exceedingly painful, but she had a quantity of white lead ready, and this she rubbed into her back as well as she could. When she could bear the pain no longer she gave in, and was put under treatment at once, at the same time developing typical hysterical crises.

A few years later, under circumstances which need not delay us here, she developed a highly characteristic, severe hysterical paraplegia, with complete analgesia to the waist and over the whole of the rest of the left side. When she was in hospital I frequently detected her pushing pins into her left arm, and on more than one occasion I found fragments of needles broken off and left under the skin on that side. This patient was observed several times to move her legs in sleep, although during her waking hours they were immobile, blue, and cold. The reflexes were normal, except that the plantar reflex was absent on both sides; there were no contractures, no wasting, no bladder affection, no bedsores, no change in electrical excitability of the muscles.

Dr. Ormerod has published the record of a peculiarly instructive case of hysterical hemiplegia in a patient under his care when I was his house physician, in whom a skin eruption of so remarkable a nature as to make its artificial origin practically certain, developed on the 
affected side. The patient protested strongly that it came spontaneously and offered no explanation of it.

Cases like these present problems that cannot be settled by the simple device of calling the deception symptoms mythomania and raising it to the dignity of a syndrome. To my mind a strong case can be made out for the view that in many instances this need for deception or simulation (in the first case quoted it is coupled with a remarkable degree of imitation, the twin sister of suggestion) may be an expression of the hysterical mind and temperament, and its admitted association with classical hysteria ought to lead to hesitation in rejecting it. The fact that Babinski can find no characteristic signs to distinguish the hysterical from the simulated matters little, however unsatisfactory from his special point of view, for it is the state of mind preceding the development of the respective symptoms that requires meticulous analysis. The bare division into conscious and subconscious simulation is inadequate.

The same objections may be advanced in regard to another group of symptoms which many competent observers (Raymond, Pitres, Vogt, Oppenheim, \&c.), in spite of Babinski's opposition, continue to class, and rightly so, as belonging in many instances to the category of hysteria. It may be remembered that while admitting respiratory and bladder symptoms to the pithiatic class, the latter has excluded vasomotor, secretory, and trophic disturbances, since he has failed to reproduce them experimentally " in certain subjects." He cannot, of course, deny the frequent existence of vasomotor phenomena in hysterical cases, but he thinks it a mere coincidence. He does not see vasomotor symptoms more often in hysteria than in any other disease. In a very suggestible patient he has failed to evoke any vasomotor disturbance by means of suggestion. But this is not the experience of many hypnotizers, men whose good faith cannot be impugned for a moment. For the proven influence of suggestion upon menstruation, perspiration, the secretion of milk, the action of the bowels, \&c., let the reader turn to Milne Bramwell's works, or to the accounts published by the Nancy School. There is no a priori reason why the vasomotor system should not be subject to functional alterations such as can be produced in these other systems by suggestion, and that these alterations are indirectly, if not directly, psychogenic there can be no doubt.

Let me support my contention with clinical instances.

A young woman, aged 22, was admitted to the hospital in a state of complete hysterical paraplegia. It was remarked that she trembled all over when 
she was addressed. When excited, even for no obvious reason, she would pant, sigh, breathe heavily and quickly; sometimes several short inspirations succeeded each other. The rhythm of her heart was at once disturbed if anyone spoke to her. There were very pronounced vasomotor phenomena; the legs were cold, blue, and mottled; she flushed very readily; her colour heightened and paled visibly. She presented characteristic hysterical symptoms-spasm of the tongue, absolute analgesia over the legs and one-half of the trunk, aphonia, \&c. The legs were immobile and stiff, but if they were passively moved the stiffness disappeared readily by the simple device of diverting the patient's attention. There were no bladder symptoms, no bedsores, no alteration in electrical excitability, no muscular wasting, no change in the tendon reflexes, and a double flexor response. The analgesia was so complete that a needle was passed through the calf without its being perceived, and without causing any bleeding.

After a strong application of the wire brush the analgesia entirely disappeared, and where a minute or two before she had felt nothing she now felt the needle instantaneously; and in addition, where formerly a vasomotor defect had prevented bleeding there was now bleeding whenever the skin was pricked.

Without entering here into the minute analysis of this striking case, I may simply remark that it is a sin against nosology to classify the analgesia as hysterical, but to reject the vasomotor disturbance, for it came and went pari passu with the former. Of the psychogenic origin, directly or indirectly, of the vasomotor impairment I can entertain no doubt. The patient made an uninterrupted recovery, which has been maintained.

Another young woman with a neuropathic family history was admitted to hospital suffering from hysterical fits, hysterical tremors, and hysterical paraplegia. She was very emotional, had attacks of dyspnœa on the slightest provocation, and choreiform movements whose intensity was in direct proportion to the attention paid to them. Whenever anyone sat beside her bed she at once began to pant. Her analgesia was such that while I was examining her she snatched the pin out of my hand and drove it repeatedly into her right arm, and into her legs, remarking that she did not feel it unless it was driven in deeply. Janet's sign was elicited with the greatest ease over the thorax. The legs were absolutely immobile, bluish and mottled, and always cold. Passing a pin through the skin produced no bleeding.

Under appropriate treatment this patient made a complete recovery, and with the return of sensibility in the legs the vasomotor symptoms entirely disappeared.

There is no need to multiply instances, especially since so many observers are at one on this point. I can see no adequate grounds for the assertion that the mechanism of the production of the one symptom 
is different from the mechanism of production of the other; on the contrary, the likelihood of their having an identical origin is extreme.

The difficulty arises from the compulsion whereby Babinski must, for his theory's sake, refuse to recognize any symptom which is not the exclusive appurtenance of hysteria. He wishes to define not merely the characteristic symptoms of hysteria, but also the distinguishing features confined to that neurosis, and if we get vasomotor changes in other conditions, they cannot ipso facto belong to it. It is the artificiality of this method of procedure which has evoked a greater chorus of disapprobation than any other of the changes Babinski has introduced into the conception of hysteria.

The same observer, it is true, has published a case in which stimulation of the sole of the foot produced the phenomenon of "goose-skin" over an area on the antero-superior part of the right thigh. Without touching the skin, however, but by the simple remark that the "gooseskin" was about to appear, he has been able to make it appear. $\mathrm{He}$ thinks that its origin in suggestion is only apparent. Once the reaction begins it is under no control, and neither the volition of the patient nor of the observer can fix its site, form, intensity, and duration. But in a true case of hysteria, such as an hysterical monoplegia, the observer can control its form or duration at will.

It does not seem to me at all certain that the response of an hysterical patient to a suggestion can always be determined as far as the site, form, intensity, and duration of the reaction are concerned. And once the reaction takes place surely the volition of the patient has no influence on it.

(c) Hysterical symptoms may arise in other ways than by suggestion.

As has been once or twice mentioned in passing, Babinski attempts to minimize, if not entirely to explain away, the influence of emotion as a factor in the pathogenesis of hysterical symptoms, and as this is a matter of no little importance for his views it must be referred to with some minuteness. We must remember that even though a symptom does apparently arise as the result of an emotional shock, that is not evidence that Babinski might not be able to reproduce it with exactness in some other individual, hence it would come under the scope of his pathogenic standard; but as a matter of fact, he thinks the difficulty of excluding the action of suggestion or auto-suggestion, in connection with the appearance of any given hysterical symptom, so serious that it is the only mechanism, for all practical purposes, that he is willing to recognize, and as an offset to this he specifies the emotional factor in particular as being, in his opinion, negligible. 
The apparent origin of hysterical phenomena in emotion is a circumstance of every-day occurrence. I was coming home one evening in a crowded tramcar from Buffalo Bill's Wild West Exhibition, and most of the passengers were somewhat elated by the rather exciting scenes of which we had been witness. A young woman seated opposite was, I noticed, particularly talkative and enthusiastic. Just as we were passing a certain house, someone in it accidentally set fire to the curtains, and in a moment the window was full of flame. Several of the passengers crowded to one side to look at it, while the young woman gave a shriek, and went off into one of the most typical hysterical fits I have ever seen. A simple illustration such as this will serve my purpose well enough, since we wish to subject the mechanism of the attack to scrutiny.

Babinski's first reply is that the spontaneity of the phenomenon is only apparent, inasmuch as the patient has probably seen something like it somewhere else, or has suffered from such attacks before, and is merely reproducing by suggestion, or rather auto-suggestion, what she has previously. experienced. If we should be able to say, as of course I cannot in the particular instance I give now, that the patient had never consciously been witness of any similar attack before, then Babinski will reply that we cannot be sure she is not a mythomaniac who is feigning convulsions-an easy thing to do-in order to attract attention to herself. As a matter of fact, this drawing of attention to one's self is one of the characteristics of the hysterical temperament, as of the child's. I noticed at the time that the young woman sank, as if by accident, into the arms of a complete stranger (of the opposite sex) seated near her, whose embarrassment was as great as hers apparently was when she recovered. Hence we cannot prove that a fictitious element was wanting in the incident, but we do not thereby lose sight of the fact that emotion was the spark that produced the hysterical explosion.

Similarly with the cure of hysterical patients, under the influence of emotional stress, Babinski declares that the habit of assuring patients they will some day make a complete recovery is a form of persuasion which we may suppose has its due effect in time, and that when the hysterical paraplegic, bedridden for years, rushes suddenly from his bed on the cry of "Fire," it is permitted to conjecture that the thought of what has (perhaps) been so often told him by some odd association enters his mind simultaneously and exerts a therapeutic action. Hence it is not the emotion which cures, but the latent idea of cure. Whether the instinct of self-preservation is not more likely to assert itself than the 
idea of cure instilled laboriously, and only partially assimilated, is matter for discussion; "sauve qui peut" is a stimulus of greater potency, it seems to me, than " you will get better some day: oh, yes, you will get better" ; and the plausibility or otherwise of Babinski's conjectural explanation must be left to the judgment of the individual. If he is dissatisfied, then Babinski offers another interpretation. According to him the pithiatique has to devote his attention subconsciously or unconsciously (the exact manner of this is not clearly explained by Babinski) to his paralysis; otherwise he is simply a malingerer, but an emotional shock will divert his attention, and he naturally recovers the use of his limbs; when the idea of powerlessness returns to his mind, he notes that for some moments at least he was able to move them, hence he is already persuaded of the possibility of a cure, which is all that is required to effect it. Assuming the psychological accuracy of this description, the explanation is feasible, and possibly some such mechanism might explain the case already quoted (p. 312), but why the influence of emotion should be ignored when, without its impulse, the patient's attention would never have been diverted at all, I am at a loss to understand. At the discussion, Pitres and Janet, among others, expressed the opinion that a simple, "cold," idea, devoid of affective concomitants, was not calculated per se either to provoke or to cure hysterical symptoms.

Pace Babinski, there are cases where hysteria develops independently of either suggestion or simulation. Various illustrations were given at the discussion, notably one by Dejerine, where a well-known scientist, as the result of a shock in a slight railway accident, developed unmistakeable symptoms of hysteria in a day or two. Let me quote one which has recently come under my observation, which has been examined especially in view of Babinski's contentions, and in which it seems to me only one conclusion is practical or even possible.

A woman of perfectly normal, good, general health, without any previous neurotic or neuropathic incidents worth remarking, was washing the stairs in her mistress's house one forenoon. These stairs were wooden and lead-covered at the edges, which were considerably worn. When walking down them, just after they had been washed, she slipped, struck her head and her back, and rolled down about seven steps till stopped by a turn in the stair. She was not unconscious. Her mistress heard the noise and came to pick her up, asking if she had hurt herself. The reply was, "I've hurt my back, I'm sure, and, I think, my head." The patient.was assisted to her bedroom, and her mistress helped to undress her, and to put her to bed. Whilst this undressing was proceeding the patient said, "I must have fallen on my right hand; I can't feel it; it's all so numbed, and I can't unbutton properly with it at all." Her 
mistress agreed perhaps she had fallen on her hand, but said it would soon come all right again. While the patient lay in bed she kept feeling her right hand and arm with her left, and was certain there was something wrong which she could not understand. Her mistress came again to see how she was getting on, and took the affected right arm into her own hands to rub it. The patient said," "I can't feel what you are doing at all; I've tried lying on my arm to restore the circulation" (thinking it was a question of the circulation), "but it's no use." The mistress then took out a penknife from her pocket, and tried with the point of it, but her maid could feel nothing. At last the latter said, "I do not believe if I were to put my fingers into the door I would feel anything."

When this patient came into the hospital she presented the most exquisite symptoms of hysterical hemiplegia, subjective and objective, that can be imagined.

Now, in a consideration of this striking case, let the significance of the following points be duly estimated :-

The patient was in full normal health at the time of the shock, and had been up to the moment of the shock.

She had never shown any hysterical symptom before, and had not the slightest acquaintance with the disease.

She personally was as astonished as anyone at the immediate appearance of the phenomenon of numbness and loss of feeling, which she noticed while she was undressing, and attributed to "the circulation."

Her ignorance of its mechanism was complete.

She satisfied herself that she had lost feeling on that side before even her mistress, who knew nothing about medicine, tested her.

She was not seen by a doctor till some hours after the accident, when the pheniomena of hysteria had already developed.

On objective examination she presented the typical features of hysterical hemiplegia.

Her symptoms are disappearing under the influence of persuasion.

A case such as this must be considered on its merits. It is entirely beside the point to quote Babinski's statement at the discussion: "On ne peut jamais affirmer qu'un malade n'a pas été suggestionné." As far as the most careful cross-examination can go, it must be acknowledged that no suggestive element could be discovered. I have every right to quote this case as one in which the action of suggestion, auto- or otherwise, can be excluded. Then why not freely admit that the shock produced the phenomena? Why not allow that they can come into being without an appeal to a hypothetical factor? Why strain the facts to fit the theory? If it is admitted, as I contend, with others, it must be admitted, that in some 
cases at least preceding suggestion in any of its varieties cannot be detected, then the absoluteness of Babinski's criteria vanishes, and his interpretation of hysterical symptoms becomes one possible explanation among other possible explanations, but no more. His views can in no sense be said to constitute an hypothesis of hysteria, comparable in the pathological field to the Darwinian hypothesis of evolution in the field of biology. The attribute or characteristic of hysterical symptoms vaunted by him as pathognomonic is not of universal applicability.

I do not know that we need delay over the arguments advanced by Babinski to minimize the importance of emotion or emotional shock as an element in the evocation of hysteria, such as its absence in the victims of the Messina earthquakes (in the Valparaiso earthquake hysteria did develop), or the rarity of hysterical outbursts on the part of visitors to the mortuaries of some of the big Paris hospitals. The circumstances in the latter case and in those where hysteria develops from an unexpected emotion are not comparable. Nor is it any refutation of the significance of emotion to insist that humanity is always swayed by the same passions, that the emotions of mankind do not change ; that, accordingly, the frequency and form of hysterical affections ought to be always identical, under ordinary conditions, which they are not. Surely this is not advanced as a serious argument. It is a commonplace of observation that both the individual and the race vary enormously in their reaction to an emotional stimulus. Gustave le Bon remarks that in the eighties of last century the telegraphic announcement of an insignificant reverse at Langson provoked an explosion of fury in Paris and France, and brought about the instantaneous overthrow of the Government, whereas at the same moment a much more serious reverse undergone by our English expedition to Khartoum produced only a slight emotion, and no ministry was overturned. The traveller in Brazil will tell us that the two individuals who have drawn knives and seem in imminent danger of receiving the coup de grâce any moment are not sworn foes, but are merely discussing whether a certain street leads to the railway station, or away from it. The difficulty of deciding where to go and what to have for dinner may entail a similar performance on the part of two Italians. Why multiply instances? The response to an emotional shock will depend on the mental content of the individual, and because the stimulus is identical in any two cases its exteriorization in the guise of hysterical symptoms need not always, in fact cannot always, be the same in form and substance.

(d) Babinski's views do not afford insight into the fundamental problem of the hysterical mind. 
"Suggestion" and "suggestibility" are words that come glibly to our lips in these days. They cover a multitude of diverse, and sometimes conflicting, phenomena. The field of suggestion is so wide that we can scarcely tell where the physiological ends and the pathological begins. The literature on the subject is bewildering in its extent. The public mind is permeated with the idea; it is part of the soi-disant scientific novelist's stock-in-trade. We must, however, essay a very brief résumé of our knowledge on the subject.

Suggestibility is normal or physiological in the case of the child. The younger members of a family sit round the study table in the evening and learn their lessons. One stammers slightly, intentionally or unintentionally, and is consciously or unconsciously imitated by the others. The imitation proceeds apace, if unchecked, until all are affected. One only, however, may become a confirmed stammerer, the others do not. Or, when books are put away they sit round the fire and make faces at each other; eventually one may develop a facial tic, the others do not. Imitation is essentially a form of suggestion, according to Babinski, and the children are all equally exposed to its influence. That some should respond more than others to its action can only mean that there are innate differences in their powers of inhibition. But even though all the members of the family should have developed tics or stammers, of longer or shorter duration, we should not have been astonished. Dubois observed an epidemic of hysterical chorea in a boarding school in Berne. Thirty girls were affected with articular pains and rhythmic movements of the arms, but isolation speedily cut short the attacks by reducing the facilities for imitation to nil. Dubois finds it difficult to believe that all were budding hysterical patients; "suggestibility has no limits in the normal mind of the child because of the insufficient development of the reason." Had the symptoms persisted in any particular case or cases, then we should find it necessary to postulate another etiological factor besides that of suggestion.

Intelligent adults can voluntarily allow themselves to be influenced by suggestion to a remarkable extent. It is the opinion of such authorities as Forel, Bernheim, Moll, Krafft-Ebing, that more than 75 per cent. of normal individuals are suggestible. Forel goes so far as to assert that every mentally healthy man is naturally hypnotizable. All experienced operators agree that the refractoriness of patients to suggestion is in inverse proportion to their sanity and strength of will. A normal individual can voluntarily submit to suggestion, as a child does involuntarily. In view of these facts, to which also Dr. Milne Bramwell 
says his experience bears abundant witness, it is our bounden duty to give up the notion that suggestibility is in itself a symptom of disease. To be suggestible and to be hysterical are not synonymous. The truth of these statements was emphasized by various speakers at the discussion, so that Babinski found it necessary to specify a valeur péjoratif to attach to the suggestion, whereby its acceptance on the part of the patient was pathological and not physiological. By this is meant that the suggestion is an "insinuation mauvaise." Yet it is exactly this "insinuation mauv ise" which the experienced hypnotist can produce in a large propor' 'on of normal subjects. Crocq, Dupré, Ballet, Vogt, Dejerine, Dubois, and others, agree that suggestibility cannot possibly be utilized to describe sufficiently and exclusively the hysterical mind. ${ }^{1}$

We may be willing to grant, no doubt, that a peculiar susceptibility to suggestion is encountered more frequently in hysterical patients than in any other disease. They respond so readily to influences from without that the observer cannot fail to be struck by it. So universal is the experience that Babinski and others would raise the symptom to the pathognomonic level. But even where suggestibility is pathological, it is not confined to hysteria. The hysterical subject may be a prey to morbid self-suggestions, so assuredly is the neurasthenic. Dubois has abundantly exemplified the truth of this. In general paralysis, chronic alcoholism, Korsakow's psychosis, there is marked increase of

1 I cannot refrain from quoting one or two passages from the immortal Burton, which will serve to correct our perspective if we are inclined either to attach the merit of entire novelty to Babinski's views, or to doubt the universality of the action of suggestion and persuasion. Truly there is nothing new under the sun. "Men, if they see but another man tremble, giddy, or sick of some fearful disease, their apprehension and fear is so strong in this kind, that they will have the same disease. Or, if by some soothsayer, wiseman, fortune-teller, or physician, they be told they shall have such a disease, they will so seriously apprehend it, that they will instantly labour of it. . . . Dr. Cotta, in his "Discovery of Ignorant Practitioners of Physick," cap. 8, hath two strange stories, to this purpose, what fancy is able to do ; the one of a parson's wife in Northamptonshire, An. 1607, that, coming to a Physician, and told by him that she was troubled with the sciatica, as he conjectured (a disease she was free from), the same night after her return, upon his words, fell into a grievous fit of a sciatica; and such another example he hath of another good wife, that was so troubled with the cramp, after the same manner she came by it, because her Physician did but name it. . . .

"As some are so molested by phantasy, so some again by fancy alone, and a good conceit, are as easily recovered. We see commonly the toothache, gout, falling sickness, biting of a mad dog, and many such maladies, cured by spells, words, characters, and charms ; and many green wounds by that now so much used unguentum armarium, magnetically cured. . . All the world knows there is no virtue in such charms, or cures, but a strong conceit and opinion alone. . . . The like we say of our magical effects, superstitious cures, and such as are done by mountebanks and wizards. An Empirick oftentimes, and a silly Chirurgeon, doth more strange cures than a rational Physician. Nymannus gives a reason, because the Patient puts his confidence in him, which Avicenna prefers before art, precepts, and all remedies whatsoever. 'Tis opinion alone (saith Cardan), that makes or mars Physicians, and he doth the best cures, according to Hippocrates, in whom most trust." (Anatomy of Melancholy: Part I, Sect. II, Mem. III, Subs. III. Shilleto's Edition, vol. i, p. 295.) The magic of a name means as much to the hysterical patient to-day as thirty years since, or as in what we are pleased to call the Dark Ages. 
suggestibility. I see little difference between suggesting to an alcoholic confined to bed that he has been for a drive round the park this morning, to which "insinuation mauvaise" he responds instantaneously by proceeding to describe what he saw and whom he met, and suggesting to a patient with hysteria that his arm is trembling, when he, too, will respond by evolving the required phenomenon. In each instance there is a reaction to a suggestion of extraneous origin without any application of the volitional brake on the patient's part. And similarly with other conditions that might be mentioned.

If we grant, however, that exaggerated or patholc fical suggestibility is one, among others, of the characteristic but not exclusive features of the hysterical mind, that is to say, if we grant that hysterical patients do, as a matter of fact, respond more readily than others to suggestion, it must be obvious that they differ from ordinary individuals, as far as suggestibility is concerned, just in this matter of readiness of response; for, I repeat, the great majority of normal people can allow themselves to be influenced by suggestion, and therefore the mental state of the former must be such as to occasion the hypersuggestibility. Hence we are led to consider hypersuggestibility as a symptom and effect, rather than a cause of the mental state associated with hysteria. What is this peculiar mental state which has augmentation of suggestibility for a symptom?

We must look elsewhere than to Babinski's conceptions for the answer.

\section{ChaPter II.}

\section{Janet's Conception of Hysteria.}

For twenty years and more the theory of hysteria enunciated and advocated by Janet has been before the medical world, which has had ample opportunities of testing his conclusions and criticizing the data on which they are based. Janet is not one of those who appeal to the results of therapeutic experience for confirmation of their theories, and he has himself acknowledged that there are certain hysterical symptoms difficult of explanation on his own hypothesis. His is a frankly psychological theory of the neurosis, according to which the somatic symptoms are the manifestations of underlying psychical disorders, which are characteristic of the disease. The student of the history of such an old-world disease as hysteria knows that the point of view from which it has been considered has varied greatly from one 
epoch to another, and if this point of view may be taken to be a reflex of the mental outlook of the age in which it has found an expression, then we should expect the twentieth century interpretation of hysteria to be sought in the realm of mind, for this is a time when many would assign all the ills to which flesh is heir to a pure disturbance of mind, and when psychopathy and psychotherapy are journalistic commonplaces. A majority of the modern conceptions of hysteria concur in the psychical "why" of hysteria; opinion is divergent on the "how." We shall see later the importance to be attached to the mechanism of the production of hysterical phenomena.

Now Janet has done no less and no more than any of his predecessors and contemporaries in the study of the hysterical problem; he has tried to discover some general distinctive marks with which to stamp the character of hysterical disorders. He believes he has found a common factor underlying the phenomena, however manifold they be, which may be expressed by the single word "amnesia," or, more generally, "absent-mindedness." From the simplest hysterical disturbance of sensibility, or motion, to the most elaborate hysterical fugue, this element of amnesia may be traced in all.

Instead of making a commencement with the familiar signs and stigmata of the disease-the palsies, contractures, and anæsthesias of the text-books-Janet takes the hysterical fit or convulsion as presenting in its simplest form the amnesia which is the essential psychological abnormality of the neurosis, and passes therefrom, by easy gradations, to the complex hysterical fugue on the one hand, and the elementary loss of sensation on the other. The change our nosological conceptions of hysteria have undergone since the days of Charcot is nowhere more apparent than in the way in which the systematization of the outward expression of the hysterical fit has been subordinated to a searching analysis of the psychical substratum. Scan the pages, study the beautiful drawings, of Paul Richer's "Hystéro-epilepsie," and then, when mind and eye are almost bewildered by the diversity of the phenomena, remember that there is an underlying unity in the common factor of amnesia. Indeed, since many "attacks" have nothing convulsive about them, Janet adopts the term "hysterical somnambulism," to exemplify the type of seizure which illustrates his views. Under the stress of some emotional shock, at the bidding of some imperious but not consciously appreciated impulse, the hysterical patient falls into a half faint, a reverie, and loses touch with his immediate surroundings; his voluntary activity comes to a standstill; the somnambulism has already com- 
menced. He lives some scene over again; goes through some action, amounting often to a sort of "performance," with quickness and precision; he gives himself up to the thraldom of some idea, and obeys it to the exclusion of all others; stimuli from without do not reach him by the ordinary avenues of sense; he is in a dream, he is living for the moment in a microcosmos, which is the sum of his memories and sensations for that time.

When he comes back to consciousness, when he recovers his full personality, as represented by the sum of innumerable memories and sensations, he has utterly forgotten the scene which he has just enacted; it is out of his consciousness, and has apparently left no trace behind. Yet, should the exciting cause of the somnambulism reappear, he will inevitably sink into the former state, and repeat the performance to its minutest detail.

Such is a "monoideic somnambulism," a psychical state consisting in the detachment of a small system of interrelated ideas from the infinitely greater complex of ideas, whose coherence constitutes the individual's personality or entire consciousness; this system of ideas, set free and developing on its own account, in the absence of inhibition, becomes for the time being dominant. With the return of normal consciousness, not only is this disaggregated or dissociated system forgotten, but in the majority of cases the idea which awakened it into activity is also forgotten; in other words, the amnesia is retrograde.

Polyideic somnambulisms and hysterical fugues are but transformations or elaborations of the simpler variety. A system of images with subsidiary systems in association is separated from the totality of consciousness, in which it leaves a blank, represented by an amnesia; once it is emancipated, once the mechanism is set going which liberates it, it develops on its own accord; by association one system after another is aroused, and so on almost indefinitely. Let me give a concrete instance to illustrate Janet's hypothesis.

A young man came into hospital with a history of fits, the exact nature of which had not been determined. One of them observed during his stay in hospital was of the following description: About 8.30 p.m., one evening, he said he was going to have a fit. When we reached him he was lying on his back in a cruciform attitude, his hands firmly grasping the edges of the mattresses (which were on the floor). He was breathing in rapid gasps, with an occasional short grunting cry, as of painful effort. His head was bent backwards, and his back arched. All the movements he made were definitely 
purposive. He recovered in a minute or two, and was quite rational, but immediately thereafter he became stiff in the trunk, stretched out his arms again as before, feeling for the edge of the mattress; the head went back, and the back arched. Then the movements became confused, and he turned and twisted in various directions. This sort of thing was repeated three or four times, after the last of which he cried out something like "Goodbye, goodbye!" and suddenly, while on his back, began to give military commands. "Form fours. . . . Right!" "Double up with those machines there," and so forth-all given loudly and accurately, and with a good word of command. (The patient was an officer of the volunteers, and had drilled a cycle corps.)

After this he rose to his knees and began to put up his hands as if boxing. He came for us, who were looking on, as if he saw us, but did not rise from his knees-striking with both hands in very good style and with great force, but without any precision. He hit his fists hard against the wooden partition of the cubicle, inside which the "performance" was being held. He repeated all this about three times, then lay still.

Then, from where he lay, he suddenly began to give hunting cries in a loud voice and realistic manner. "Harmony! Harmony! Harmony!" "In at 'em! . . ." "Hoick! Hoick! . . ." "Gone away! Gone away! . . ," \&c. (He had been fond of hunting, in particular of otterhunting.)

Then he mentioned some man by name, and talked of a girl of his acquaintance, rattling on somewhat as follows: “___, you blackguard. As soon as your sister's out of the room you begin to talk like that. You are a scoundrel, a damned scoundrel. . . . No, I daresay you don't like it," \&c. He then became quiet again, and in a minute or two was in a normal state. He had no memory of the details of his little rehearsal. ${ }^{1}$

Janet's explanation of the psychological mechanism of such elaborate attacks affords much insight into their character.

When we proceed in the direction of the less complex phenomena of hysteria, we learn that a large number of minor attacks and crises are nothing else than imperfect somnambulisms. There is order behind the apparent disorder of the hysterical attack; the movements are subjectively purposeful, however purposeless they may objectively seem. The young woman who falls full length on her bed as the physician enters the ward to make his round, and lies there with quivering eyelids and shaking limbs, sighing and panting, her arms extended in cruciform attitude, is not a puppet or a mechanical doll; there is method in her madness; she is an actress, but she does not know that she is acting. Fifty years ago Briquet wrote that a fit of simple hysteria is nothing but the exact

1 This description is taken in part from the notes of Dr. Carmalt Jones, who was one of the house physicians at the time and witnessed the attack. 
repetition of the disturbances by which vivid and painful moral impressions are manifested, and in many cases it is possible to distinguish and recognize the particular emotion that finds expression. In other words, a dissociated idea or system of ideas establishes itself, to the exclusion of all others, in an emotional form, in a cruder and coarser fashion than in the seemingly intelligent action of the somnambulism.

Janet further illustrates his general principle that amnesia or absentmindedness can be traced in all hysterical phenomena by a consideration of the familiar motor and sensory symptoms, the tremors, spasms, contractures, and palsies, the anæsthesias, hyperæsthesias and points douloureux. We cannot follow his lead through them all, and Janet's views are familiar enough to the neurologist. Suffice it to say that the will of the subject has no influence on these symptoms, and that consciousness does not seem to have a great hold on them either. Some function or functions, such as that - of moving the arm or the leg, is separated from consciousness, and motor activity, disaggregated in this way, may assume various forms. On the sensory side, the ensemble of sensations coming from the arm or the leg form a kind of system which can no longer be connected with the totality of consciousness, although it still exists on its own account and may even determine reflexes and ordinary movements. Hysterical anæsthesia is essentially a species of absent-mindedness. There is in it a pathological incapacity on the part of the patient to connect with his personality the sum of the particular sensations concerned. A similar explanation may be furnished for the impairment of the special senses so frequently encountered. A résumé of the conclusions to be drawn from Janet's investigations is supplied by himself in a form somewhat as follows:-

"Hysteria is a disease of the mind and belongs to the large group of maladies occasioned by cerebral depression or exhaustion; its physical accompaniments are vague enough, consisting chiefly in a general diminution of nutrition. It is characterized principally by mental symptoms, of which the most important is impairment of the faculty of psychological synthesis, an aboulia, or constriction of the field of consciousness, manifesting itself after a special fashion; a certain number of elementary phenomena of motion-sensations and images-cease to be perceived and appear to be excluded from full conscious personal perception: hence there is a tendency to a permanent and complete division of personality, and to the formation of several independent groups. These psychological systems either alternate or co-exist. 
Finally, the defect of synthesis favours the development of certain parasitic ideas which evolve by themselves and in their entirety under cover of the control of personal consciousness, and which manifest themselves in markedly variable disturbances in appearance solely objective."

The conception has been put more briefly in Janet's latest work, and is there couched in the following terms:-

Hysteria is a form of mental depression characterized by the retraction of the field of personal consciousness, and a tendency to the dissociation and emancipation of the systems of ideas and functions that constitute personality.

We shall better understand the full meaning of this condensed statement if we take a glance at Janet's analysis of the hysterical mind. He has replaced the classical stigmata of Charcot by others of a totally different nature, psychical and not physiological. These new stigmata, however, Janet is careful not to endow with any attribute of absoluteness, although some are, in his opinion, scarcely to be found in any other condition than hysteria. It is impossible, even if it were desirable, completely to isolate or insulate the neurosis under consideration from all other neuroses; yet it is, of course, a special form, and can be more or less distinguished from the rest. Of the stigmata that characterize the hysterical mind there are two groups :-

(1) Some are common to Hysteria and to other Mental Disturbances.

Hysterical patients are neuropaths first of all. They reveal a curious combination of emotionality and of apathy; they are both sensitive and indifferent. They must needs attract attention to themselves, yet they evince no aptitude for attention; they lapse into reverie; they are often unable to retain recent impressions. What Janet has called "feelings of incompleteness" are frequently met with in hysteria; the patients " are perpetually tormented by a vague ennui which they cannot overcome." Among other defects of mental function disturbances of the will occupy an important place. Inability to will, to begin a particular action or to inhibit it once it is begun, is universally recognized as a common feature of hysteria, as much so as of psychasthenia. One of Janet's patients put it very neatly: "I fall into an idea as down a precipice, and the declivity is hard to climb again."

The general result of these defects, not exclusively characteristic of hysteria, however frequent their occurrence in that neurosis, is a lowering of the mental level, a form of mental depression. 
(2) Some appear to be proper to Hysteria.

(a) Suggestibility. - I have already remarked that consensus of medical opinion assigns to suggestibility a place of paramount importance for the development of hysterical phenomena. That it should be proclaimed the sole criterion whereby to judge hysterical symptoms is not feasible from a practical standpoint, and is psychologically untenable. We willingly grant, however, as I have shown, that there is a pathological suggestibility highly, though not absolutely, characteristic of hysterical states. The feature of this abnormal suggestibility is that the idea which is suggested develops to an extreme, without participation either of the will or of the personal consciousness of the subject. Janet himself holds that the term suggestibility should be restricted to this pathological variety, and he agrees with Babinski to some extent on this point. As the latter has said, it is a matter of terminological convention whether suggestion is to be applied solely to the form that has just been mentioned. Be this as it may, it is unnecessary to repeat here the objections previously urged to the view that considers pathological suggestibility a unique feature of the hysterical mind. What is much more important is to appreciate the fundamental difference of attitude between Babinski and Janet in the discussion of the significance of suggestion. Janet's position is that this suggestibility is itself dependent on another factor. If an individual reacts blindly to a pathological suggestion, it is because he is no longer capable of controlling, investigating, deliberating on the ideas presented to him. A sine qua non for the fruitful development of a suggestion is the absence from the patient's field of consciousness of ideas antagonistic to the suggestion. As .Janet says, its strength rests on the astonishing ignorance of the patient. Objections, impossibilities, contradictions, do not reach his mind. Thus suggestibility is an effect, not a cause: "absent-mindedness" allows it, and precedes it.

(b) Absent-mindedness is the second feature of the hysterical mind. There is a suppression of all that is not looked at directly. We have already seen how intellectually satisfying is the explanation by amnesia or absent-mindedness of so many of the diverse symptoms of hysteria, and need not enlarge further on the subject in this place. What we must note here is simply the logical extension of the hypothesis, so that suggestibility itself is included among the symptoms dependent on amnesia.

(c) Another characteristic of the hysterical mind, according to Janet, is the tendency to transfers and equivalents. No one with any 
clinical experience of hysteria but has been struck by the alternation in symptoms so frequently met with. It would be superfluous to cite instances of so banal a phenomenon. One symptom disappears only to be succeeded forthwith by another. Janet thinks there is something peculiar to hysteria in this special form of instability, although sudden alternation in symptoms is by no means unknown in other conditions. I have seen spasmodic torticollis alternate, by periodic transitions, with delusional insanity. When the patient was insane there was no torticollis: her intervals of complete sanity, on the other hand, were accompanied by the wryneck.

These characteristics of the hysterical mind may be summarized into a single general idea, to express the fundamental element in the psychoneurosis, viz., "retraction of the field of personal consciousness." This brings us back to our definition already quoted, so that we have learned the steps by which Janet has reached it.

If the field of personal consciousness be thus restricted it is not to be imagined that all impressions not reaching it, not synthetized with it and made a part of its content, are lost. On the contrary, they reach and produce their due effect in a secondary or subsidiary consciousness, which is a necessary postulate for a complete psychological explanation of Janet's conception of hysteria. Thus consciousness is regarded as being split or doubled; and we are at once introduced to the multitudinous and complex phenomena of the so-called subconscious mind.

It is true the extent to which the psychological conception of a subconscious mind has been enlarged is scarcely credible: to its activities are ascribed our virtues and our failings, our inspirations and our enthusiasms : it is the source of inventive genius : it is the means whereby God speaks to man: subconscious telepathy and the Communion of Saints are synonymous terms, \&c., \&c. The old Scottish advocate, who on the night before his cases came up for decision, used to read over his briefs to the accompaniment of copious draughts of his national beverage, and who attributed his success to letting everything "whummle in his wame" during the night, had not heard of the subconscious, probably, else his theory might have been expressed more scientifically, though not necessarily more lucidly. Janet quotes an amusing saying of Hartmann : "Let us not despair at having a mind so practical and so lowly, so unpoetical and so little spiritual: there is within the innermost sanctuary of each of us a marvellous something of which we are unconscious, which dreams and prays while we labour to earn our daily bread." It is quite beyond the purpose of this rapid review even to 
mention the various theories of the action of the subconscious mind, or to delay where hysterical phenomena are concerned by endeavouring to supply an interpretation based on that action. It is sufficient, and at the same time it is only fair to Janet to state, that he expressly confines. himself to a purely clinical, and, as he says, somewhat prosaic, use of the word "subconscious." He employs it to characterize perfectly commonplace phenomena, with which all students of hysteria are familiar. An hysterical patient, with an arm and hand completely insensible to all forms of cutaneous and deep stimuli, will, if the observer put a screen in front of the patient's eyes, and then impress a series of alternating flexion and extension movements on a particular finger, nevertheless continue to make two or three movements with his finger after the operator has ceased. That the finger should spontaneously repeat the movement, the latter must have been perceived. Yet the patient insists that he felt absolutely nothing. A psychomotor act has been performed without the patient's conscious knowledge : it is a subconscious phenomenon. The mental processes involved are disaggregated from the conscious personality of the patient: they are for the time "on their own."

Take a second illustration of a rather different sort. Some years. ago in a little village in the Harz Mountains I witnessed a performance by "La Madeleine," who, as her professional descriptive title of "Schlaftänzerin" indicated, danced to music while she was in a state of hypnosis. It was easy to satisfy oneself that the performance was. genuine, as opportunities were afforded medical men of examining her when she was in this state. As the music rose and fell, or changed from sad to gay, quick to slow, passionate to soothing, so La Madeleine altered her steps, her rhythm, her gestures, in perfect harmony, at length ceasing abruptly ere the pianist had finished. She heard and perceived the auditory impressions and responded to them intelligently, while at the same time she was completely unaware of what she was doing. The sensory stimuli were not connected with, or merged in, her personal consciousness. It is to phenomena such as these that Janet applied the term "subconscious"; he offers no theory of subconscious mechanisms, be it noted, but simply utilizes the conception to complete his psychological interpretation of hysteria.

Janet's interesting and attractive opinions are, I believe, as far as they go, the most satisfying of the various psychological explanations of the disease that have been proposed. They serve better than any other to bring into relief the essential nature of hysterical disorders. 
Whatever alterations in our ways of regarding the neurosis subsequent investigation may effect, it cannot be considered as other than a disease of the highest or psychical level. At this stage of our knowledge it is like sending owls to Athens to cite instances in support of this contention, yet I may be allowed to quote briefly one or two little incidents of clinical observation that have to me been very instructive.

A young woman came into hospital with an hysterical monoplegia of the left leg. There was complete insensibility to stimuli of cutaneous origin over the skin from the knee down. So absolute was this insensibility that a pin could be passed through the skin without her feeling any pain. When I produced a Cattell's algometer, an apparatus of the nature of which she was in ignorance, and pushed it into the left calf, to my astonishment she cried out with pain when the instrument had only registered 4-a normal response. On testing her skin condition again, the anæsthesia had disappeared.

One may suppose that the patient had a certain mental image of her left leg, compounded of various secondary sense memories and images. This mental image or system was for the time being dissociated from the patient's totality of systems, constituting her conscious personality. Hence she felt no pain when the leg was stimulated. As, however, there did not happen to be included in this disaggregated mental picture of her limb the element belonging to deep sensibility, whenever a stimulus reached the underlying tissues she felt it instantaneously, and with it the mental image of the limb returned to conciousness.

How can we explain, except on the view that hysteria is a disease of the level of mental images, the loss of sensibility in a case of hysterical paraplegia, where the analgesia on the back of the trunk completely differed in distribution from the analgesia on the front?

Take a still more remarkable instance.

A woman came into hospital with a complete left hysterical hemiplegia and hemianæsthesia, and impairment of all the special senses on the left. The hemianæsthesia was absolute to every form of stimulus, cutaneous and deep. In addition, the patient exemplified admirably the phenomena of so-called "Seelenlähmung"; she could not move her left arm or leg unless her eyes were open and she was looking at it. On the right side of the body there was normal sensibility throughout. When her right arm was passively put by the observer behind the patient's head, so that the right hand and part of the forearm were to the left side of the mid-line of the patient's body, she lost sensibility in that part of the limb which was to the left. It is true there was no sharply demarcated line corresponding strictly to the mid-line of the 
body; it was, however, the case that if the hand or fingers were well to the left, behind the patient's head, then they became insensitive. ${ }^{1}$

The reader will appreciate the ease with which an explanation of this extremely interesting observation can be offered on Janet's hypothesis. The disturbance of the idea of "sidedness" is an indication of the psychical level of the disease.

While Janet's hypothesis is inherently reasonable and his masterly exposition of it very convincing, there are certain symptoms of hysteria and certain types of cases to which its application is not altogether easy.

(1) Cases in which hysterical symptoms suddenly arise, after a trauma, are difficult of explanation, inasmuch as the relation of the trauma to the subsequent appearance of the symptoms is not at all obvious. If we take the case already instanced (p. 320) to show the absence of the factor of suggestion, I do not see that we learn anything as to the causa causans by saying that the field of personal consciousness is constricted, and the system of ideas relating to the right side of the body is no longer synthetized with it. In such cases the psychological explanation may be perfectly correct, but is it a pathogenic explanation, or is it not rather simply a description of the psychological accompaniments of the somatic phenomenon? In any case we learn nothing from Janet's theory as to why and how a trauma should suddenly produce an hysterical hemiplegia.

Similarly, there are many cases where hysterical symptoms appear without any evidence of any mental factor being at work.

A nurse, fatigued by overwork when on night duty, noticed one evening that her voice was husky, and the next morning found, to her surprise, that she was completely aphonic. She presented no other symptom, and had always been perfectly able to do her work. On objective examination the characteristic appearance of the vocal cords was found; they moved perfectly well and met in the middle line, in complete apposition, during a sudden retching spasm. A single application of faradism to the outside of the neck resulted in the immediate disappearance of the symptom, and effected a lasting cure. Naturam morborum curationes ostendunt.

In this monosymptomatic case there was no trace of any suggestion to be discovered, nor was there any indication to aid us in explaining its pathogenesis. How are we to attempt to elucidate this hysterical aphonia? I do not doubt that Janet's hypothesis supplies a clearly thought out explanation of the psychological features of the condition, but I can find no proof or sign of the existence of that hysterical mind which is the soil from which the symptoms are supposed to spring.

1 This observation was originally made, I believe, by Dr. Foster Kennedy, then Resident Medical Officer, and I had opportunities subsequently of observing the phenomena for myself. 
In fact, a wider objection has been raised applicable to all purely psychological theories, that one may be as correct as another in the explanation of any given case. Thus the above-mentioned patient may have been aphonic because she had a fixed idea that she could not speak above a whisper; or because she was aboulic, and could not will to speak; or because her attention was distracted from her voice; or because she was suffering from systematized anæsthesia; or because she had forgotten the representations and memory images for the movements of phonation; or because voicelessness was suggested to her, or auto-suggested; or because of the constriction of her mental horizon, so that she could not combine in one personal synthesis the sensations concerned; or because this system of impressions and representations was actually dissociated from personal consciousness.

It is true, no doubt, that any one of the above explanations may hold good in a given case. Moreover, we may be quite unable to decide between several of them, in connection with another case. The advantage of psychological theories is that any or all of them may be correct. But the fact does not invalidate the general position. They are evolved to offer interpretations of objectively observed data, and as by their inductive nature they are incapable of proof or disproof-for an induction is always debateable in the strict sense-we must choose that one with which the facts seem best to accord. Janet's views are condensed into an inductive generalization, an hypothesis, using the word scientifically which hypothesis we utilize to explain certain clinical phenomena, and we find it both reasonable and of wide application. It matters not that a totally different psychological explanation may be advanced in regard to any particular symptom or case of hysteria ; both may be true, but we cannot conceive of both in action in one and the same case. Sollier's criticism that no psychological explanation of the symptoms of hysteria is really pathogenic is immaterial; we believe in the duality of mental processes, and cannot imagine hysteria to be a disease sine materie. In the present state of our knowledge it is futile to attempt any correlation of psychology and physiology; therefore we are not concerned to discuss whether, for instance, the idea of a doubling of consciousness, or the conception of a constricted mental field, is the sequel to, or the accompaniment of, some physiological state of association neurones. It is sufficient that the conviction of the essentially ideogenic origin of hysterical phenomena demands, for our own intellectual satisfaction, a theory of the disease that is expressed in psychological terms; we do not thereby sacrifice all interest in its physiological aspect; all we say is, that speculation at present is bound to remain unproductive. Féré's 
objection to a psychological theory, that it hinders all search for a physical one, need not alarm us. We do not believe in a disease confined to the world of ideas; it must have a counterpart in the physiological world-what that may be must be left for future investigation.

(2) Vasomotor, nutritional and trophic disorders, such as are frequently found in connection with hysteria, are difficult to explain on Janet's hypothesis. A consideration of this point, however, and of a further objection, viz., that the hypothesis is unnecessary in certain cases where organic and hysterical disease occurs in the same patient, for often no ide,ogenic factor can be traced, must be left for another occasion.

I have repeatedly said that I believe we must depend on the objective signs of hysterical disease if we are to progress towards its unification. Janet himself holds that the intrinsic examination of cases of hysteria is the most accurate and scientific method. Now the chief point, as it seems to me, on which more light is wanted, is the mechanism of the production of the symptoms. Granted that a particular mental state is accountable for the disturbances of function, how are these actually brought into being? Granted that amnesia or absentmindedness causes hysterical motor defects, why have we tremor in one instance and paralysis in another? And what are the objective features of these? Can we thereby learn anything as to the seat of the functional defect? I am convinced from the study of a number of cases that organic disease will teach us far more about hysteria than vice versâ. Thus I observe a case of thrombosis of part of the medulla, and I discover that the anæsthesia and vasomotor changes consecutive to this thrombosis are in some ways extraordinarily like what is met with in hysteria. I find that the tremors, spasms, and palsies of hysteria are characterized by a certain functional defect on which much light is thrown by recent physiological research on the functions of the cerebrum. I come across cases of disseminated sclerosis with symptoms indistinguishable from those of hysteria. I observe a case of pure hysteria in which micropsia is one of the symptoms, and I compare its objective features with micropsias of known organic origin. The objective study of the symptoms of the neurosis must continue to be our task; hysteria, however psychical its background, reveals itself by somatic symptoms and signs as definite and real as those of general paralysis. I hope to return to a consideration of some of these questions, which concern the mechanism of hysterical symptomatology, and the opportunity will be taken to refer to the relation of Janet's hypothesis to them. 


\section{References to some of the more Important Publications on Hysteria by the French School.}

Babinski. "Hypnotisme et Hystérie," Gazette hebdomadaire de Médecine et de Chirurgie, July, 1891.

Idem. "Diagnostic différentiel de l'Hémiplégie organique et de l'Hémiplégie hystérique," Gazette des Hôpitaux, May 5 and 8, 1900.

Idem. " "Définition de l'Hystérie," Société de Neurologie de Paris, November 7, 1901.

Idem. " Introduction à la Sémiologie des Maladies du Système Nerveux," Gazette des Hôpitaux, October 11, 1904.

Idem. "Ma Conception de l'Hystérie et de l'Hypnotisme," Archives générales de Médecine, August 28, 1906.

Idem. " "Émotion, Suggestion, et Hystérie," Société de Neurologie de Paris, July 4, 1907.

Idem. " "Démembrement de l'Hystérie Traditionnelle: Pithiatisme," La Semaine Médicale, 1909.

Idem. "De l'Hypnotisme en Thérapeutique et en Médecine Légale," La Semaine Médicale, 1910.

Claparìde, “Esquisse d'une Théorie biologique du Sommeil,” Archives de Psychologie, 1905.

Idem. " "Quelques mots sur la Définition de l'Hystérie," Archives de Psychologie, October, 1907.

CRocq. “Étude de la Réfléctivité dans l'Hystérie," Revue Neurologique, November 15, 1907.

Idem. " "Définition et Nature de l'Hystérie," Journal de Neurologie, 1907.

JANET. "L'Automatisme Psychologique," 1889.

Idem. " "L'État mental des Hystériques," 1894.

Idem. " "Névroses et Idées Fixes," 1898.

Idem. " "Les Obsessions et la Psychasthénie," 1903.

Idem. " Major Symptoms of Hysteria," 1907.

Raymond. "Névroses et Psycho-névroses : Leçons faites à l’Hospice de la Salpêtrière," 1907. Sollier. “Genèse et Nature de 1'Hystérie," 1897.

Idem. " "L'Hystérie et son Traitement," 1901.

Idem. " "Mécanisme des Émotions," 1905.

Idem. " "La Définition et la Nature de l'Hystérie," Archives générales de Médecine, October, 1906.

Idem. "Hystérie et Sommeil," Archives de Neurologie, 1907.

"Définition et Nature de l'Hystérie," Comptes-rendus XVIIe Congrès des Médecins aliénistes et Neurologistes de France et des Pays de Langue française, Revue Neurologique, 1907, XV., p. 876 et seq.

"Discussion sur l'Hystérie," Comptes-rendus de la Socièté de Neurologie de Paris, Revue Neurologique, 1908, XVI., p. 375, p. 494.

“ Du Rôle de l'Émotion dans la Genèse dés Accidents Névropathiques et Psychopathiques;" Compte-rendu Officiel de la Réunion Annuelle de la Socièté de Neurologie et de la Société de Psychiatrie de Paris, Revue Neurologique, 1909, XVIT., p. 1551 et seq. 